\title{
Cervantes y el Quijote hacia la Revolución Francesa
}

Cervantes et Don Quichotte vers la Révolution Française

Esther Bautista Naranjo Universidad de Castilla-La Mancha

CES.XVIII, núm. 26 (2016), págs. 67-92. 


\section{RESUMEN}

En este artículo nos proponemos desgranar las variadas interpretaciones que el Quijote sufrió en Francia durante la época ilustrada tomando como referencia las obras creativas y críticas anteriores y posteriores a la Revolución de 1789. Este acontecimiento, esencial para la historia de Europa, influyó también en la exégesis de la novela en el país galo, que pasó paulatinamente de abogar por una lectura satírica de la obra cervantina como epítome de las costumbres y vicios españoles a ver en su protagonista la representación de los ideales de los oprimidos frente a un sistema social injusto y degradante. De este modo, se abrieron las puertas a la interpretación simbólica del personaje que floreció en Inglaterra y Alemania en los albores del Romanticismo.

Palabras Clave:

Interpretación del Quijote, clasicismo, Ilustración, hispanismo.

\section{RÉSUMÉ}

Dans cet article nous envisageons d'étudier les différentes interprétations que le Don Quichotte de Cervantès a subi pendant l'Illustration à partir des œuvres créatives et critiques publiées avant et après la Révolution de 1789. Cet évènement, essentiel pour l'histoire de l'Europe, a déterminé l'exégèse du roman cervantin en France, où l'on a, peu à peu, remplacé, la lecture satirique de l'oeuvre comme un symbole des moeurs et des vices espagnols par la personnification chez le protagoniste des idéaux des opprimés face à un système social injuste et dégradant. Cette approche est à l'origine de l'interprétation symbolique du personnage de don Quichotte qui s'est développée en Angleterre et en Allemagne au début du Romantisme.

MotS-CLÉS

Interprétation de don Quichotte, classicisme, les Lumières, hispanisme.

Recibido: 14 de junio de 2016. Aceptado: 25 de julio de 2016. 


\section{Introducción}

Lejos de lo que suele afirmarse por parte de la crítica, la lectura del Quijote en el siglo XVIII no resulta tan homogénea como podría parecer. Bajo el reflejo de las Luces, la obra de Cervantes alcanzó una popularidad inusitada en Francia, del mismo modo que la huella inicial, basada en la comicidad y lo grotesco, caló hondo en el imaginario británico y que la interpretación romántica surgió y fructificó naturalmente en Alemania ${ }^{1}$. Muchos factores explican la consagración de la exégesis ilustrada del Quijote en Francia, pero el importante rol de dicho país durante la época del clasicismo y de las Luces (aunque España e Inglaterra fueron también determinantes) debió facilitar el camino. Como se ha puesto de relieve, la interpretación dieciochesca del Quijote a nivel europeo pasa inexorablemente por Francia ${ }^{2}$.

En consecuencia, los estudios generales sobre la recepción del Quijote en el país galo ${ }^{3}$ se detienen en este período al mismo tiempo que es en torno a los autores de la época gloriosa de las Luces en que mayormente se centran las contribuciones exegéticas sobre la obra de Cervantes en Francia. Este hecho no

1 Sobre el surgimiento de la exégesis romántica pueden verse los libros de Anthony Cuose, The Romantic Approach to Don Quixote, Cambridge, Cambride University Press, 1978; Esther Bautista Naranjo, La recepción y reescritura del mito de don Quijote en Inglaterra (siglos XVII-XIX), Madrid, Dykinson, 2016.

2 Este predominio, que corrió paralelo al desarrollo cultural del país durante el Neoclasicismo, hizo que las ediciones y traducciones francesas del Quijote sirvieran como elemento pivotal o mediador en otras versiones que parecían basarse más en los modelos de Oudin y Rosset (1614, 1618), primeros traductores franceses, que en el propio original cervantino. Este es el caso no sólo de la vecina Italia, sino también de Hungría, Polonia, y los países bálticos, especialmente Eslovenia. Dos motivos explican la relevancia de la cultura francesa durante los siglos XVII y XVIII: 1. Francia era uno de los países más poblados y 2. El francés se utilizaba entonces como lengua vehicular a nivel europeo (Franco MEREgalLi, «Los primeros dos siglos de recepción de la obra cervantina: una perspectiva», Actas del Coloquio Internacional de la Asociación de Cervantistas, Barcelona, Anthropos, 1997, págs. 33-42; 37).

3 Jean-Paul Sermain, Le Singe de don Quichotte : Marivaux, Cervantes et le roman post-critique, Voltaire Foundation, Oxford, 1999; Maurice BARdon, Don Quijote en Francia en los siglos XVII y XVIII, Estudio introductorio de Françoise Étienvre, San Vicente del Raspeig, Universidad de Alicante, 2010 [1ª ed. 1931], pág. 918); Jean Marie Goulemot, Lydia VÁzquez y Juan Manuel Ibeas, «La locura en el siglo de la razón: visiones de Don Quijote en el siglo XVIII francés», Don Quijote en los cinco continentes. Acerca de la recepción internacional de la novela cervantina, ed. Hans Christian Hagedorn, Universidad de Castilla-La Mancha, Cuenca, 2016, págs. 261-292; 288. 
resulta baladí a la configuración global de la recepción del Quijote, pues Francia representa el paradigma de la interpretación dieciochesca, una lectura que se basa en la comicidad, la parodia y la sátira de las costumbres y vicios españoles. Si bies es cierto que esta es la interpretación predominante durante la mayor parte de la centuria, hay que percibir un cambio moderado en la interpretación del personaje y en la lectura de la obra con el advenimiento de la Revolución de 1789, a partir de la cual don Quijote dejaría de ser el emblema de la demacrada nación española (hacia la cual los franceses manifestarían una clara animadversión) para convertirse en una figura mucho más universal y desligada del localismo impuesto por su nacimiento. Aunque la interpretación mayoritaria no excluía la vertiente satírica, don Quijote dejó entonces de interpretarse únicamente como un arquetipo para convertirse en un loco absoluto, un símbolo de la equivocación humana debida a un exceso de idealismo, abriendo así el camino a la interpretación empática de los exégetas románticos.

En este artículo trataremos un tema de sobra conocido, como es la interpretación del Quijote en el siglo XVIII francés, pero lo haremos desde una perspectiva novedosa, estableciendo una distinción entre la aproximación pre- y post-revolucionaria, para establecer así un puente entre las lecturas críticas que provienen de las cómicas y las que preceden a las simbólicas. Partiremos, por tanto, de la premisa de que el surgimiento del sentimiento revolucionario corrió paralelo al advenimiento del movimiento romántico, manifestado posteriormente a través de la exaltación de los ideales individuales, patrióticos y nacionalistas a lo largo de las revoluciones liberales durante el siglo XIX. En los párrafos que siguen haremos un recorrido desde el comparatismo de Pierre Brunel y la intertextualidad (tanto explícita como implícita) en la línea de Bajtín y Genette $^{4}$ por las visiones del Quijote a lo largo del siglo XVIII tomando como eje central la Revolución francesa. Este panorama se compondrá de traducciones, comentarios, alusiones, imitaciones..., - manifestaciones directas o indirectas de dicho diálogo intertextual con el precedente cervantino- y nos ayudará a valorar en qué medida la Revolución de 1789 pudo influir en el surgimiento de la interpretación romántica del ingenioso hidalgo.

4 Pierre Brunel, Précis de littérature comparée, París, P.U.F., 1980; Mijaíl Bajtín, Problèmes de la poétique de Dostoüevski. París, Seuil, 1970; Gérard Genette, Palimpsestes. La littérature au second degré, París, Seuil, 1982. 
Para comenzar, hemos de precisar que, aunque las traducciones francesas posteriores a Oudin y Rosset no revistieran gran hondura durante tres siglos (salvo, a juicio de Sermain ${ }^{5}$, la de Viardot), conviene que nos acerquemos a las que se produjeron a lo largo del siglo XVIII para conocer el tipo de lectura que prevalecía y que se quería transmitir a los que deseaban asomarse a las páginas de Cervantes en su lengua nativa.

Uno de los méritos atribuibles a la traducción de Filleau de Saint-Martin es que resulta más evolucionada que las inglesas de su tiempo. Estilísticamente, se aleja del tono cómico y jocoso y apela a la noción de decoro. Al mismo tiempo, se ofrece la historia en un lenguaje sencillo y cercano, simplificando considerablemente los excesos barrocos de Cervantes. Lo que llama la atención es la empática visión del personaje, cuya honestidad es alabada en medio de un entorno hostil. Tiene, además, el mérito de ser pionera al integrar las dos partes quijotescas por primera vez, aunque pasadas por la poda de un traductor que rebaja no sólo el tono y el estilo cervantinos, sino también todos los elementos complementarios a la narración principal, como los poemas, dedicatorias y demás ornamentos, además de tijeretear algunas aventuras para adaptarlas, según indica, al gusto francés. Filleau manipuló la intriga para no dejar morir al hidalgo, hacerle sanar, y convertir a Sancho en un advenedizo caballero al final de la historia. Asímismo, se reserva el privilegio de revivir a don Quijote en sus páginas, no sin antes haber dejado recogida su historia por el cronista Zulema.

La continuación basada en la traducción de Filleau de Saint Martin que hizo Robert Challe adquiere el tono de un pastiche. Toma de Cervantes la alternancia entre sedentarismo y vagancia, alternando los episodios de aventuras del par protagonista con aquellos en que reposan mientras escuchan los relatos de otros. Resulta de interés que Challe anuncie mediante su continuación una confraternidad respecto al desamparo quijotesco, pudiendo ver en él « un frère dans la désillusion [...] un caractère dont l'aspect contestataire puise ses sources dans l'inconformisme, dans la droiture et dans la generosité $»^{6}$.

Esta intención resulta ciertamente extraña al sentir general, pues, en líneas generales, la exégesis dieciochesca del Quijote es, en cierto modo, deudora de

5 Jean-Paul Sermain, « La fin de Don Quichotte », Mélanges de la Casa de Velázquez 37, 2 (2007), URL <http://mcv.revues.org/1667>.

6 Jacques Cormier, « La Continuation de l'histoire de l'admirable Don Quichotte de la Manche de Robert Challe. Cervantès trahi ou compris? ", Cahiers de l'Association internationale des études françaises, 48, 4 (1996), págs. 263-282; 277. 
la interpretación inicial. El humorismo encarnado por dos fantoches burlescos adquiere, desde principios de siglo, un tono más local al entenderse que el protagonista es un ejemplo de los excesos de imaginación y de optimismo de la nación española. Al tiempo que la obra se convertía en un lugar común para muchos lectores de los más diversos estratos, los círculos eruditos se apoyaron en ella para hacer prevalecer el dogma de la razón que condenaba al protagonista a la condición de loco, un loco que simbolizaba los excesos de la patria que lo había engendrado. La lectura del Quijote como una aguda sátira de los vicios españoles ha de entenderse dentro del contexto de la Leyenda Negra que se cernía sobre nuestro país (como muestran, por ejemplo, las entradas de la Enciclopedia), y que escondía razones de signo histórico, político, pero, sobre todo, de imperio.

En el polo opuesto se encuentran los adeptos o seguidores de Cervantes que van a desligarse de la corriente crítica mayoritaria para reivindicar de algún modo la herencia literaria transmitida por Cervantes en su obra, bien elogiándola o bien asimilando y/o imitando de manera más o menos velada las técnicas, la temática o los recursos cervantinos ${ }^{7}$. Dentro de la «Querella entre los Antiguos y los Modernos» que supuso un cisma dentro del Clasicismo fueron estos últimos quienes mejor supieron apreciar la renovación estilística propuesta por Cervantes en forma de novela, de modo que se adscribió al autor alcalaíno a la nómina de los «Modernos».

La paulatina debilitación de la comicidad que había regido la centuria anterior está en relación con la modernidad atribuida a Cervantes. Comicidad que, dicho sea de paso, hay que entender dentro de la escritura carnavalesca tan brillantemente estudiada por Bajtín ${ }^{8}$, quien, afirma, a propósito de Rabelais, contemporáneo de Cervantes, que, en el momento de la concepción de su obra, la risa no resulta contraria a lo serio, pues ambas sirven como vehículo de expresión de la verdad del mundo y del hombre. Al sobrepasarse la interpretación cómica surgen los procesos de apropiación de las figuras principales a las que se les atribuye diversos simbolismos. La parodia y la sátira se sirven de don Quijote para criticar todo tipo de actitudes. Además, los «Modernos» empiezan a tomar en consideración la vinculación de la obra cervantina a la categoría de antinovela, o de una literatura que reflexiona sobre sí misma a todos los niveles (tanto conceptual como de forma de escritura), al tiempo que no deja de lado ese

7 Hemos de aclarar que en este trabajo nos centraremos tan sólo en alusiones y/o imitaciones de la historia de don Quijote y Sancho. Sobre las historias secundarias se puede ver el libro de Alexandre CiorANEScu, Le Masque et le visage. Du Baroque espagnol au Classicisme français, Ginebra, Droz, 1983, pág. 543.

8 Mijaíl Bajtín, La cultura popular en la Edad Media y el Renacimiento. El contexto de François Rabelais, Madrid, Alianza, 2005. 
interés desmitificador asociado a la parodia. Entre los modernos, la principal huella de Cervantes fue la contradicción entre el punto de vista del personaje y del narrador?. Tras el declive del género cómico, al que Sermain pone la fecha de defunción en $1670^{10}$, «la gran novela española sería el pilar en el que se basó la reflexión sobre la novela en general, a partir del cuestionamiento del tópico del "peligro de las novelas" ${ }^{11}$. Pero, seguramente la mayor enseñanza que pudieron extraer de Cervantes fue su reivindicación de la libertad del arte.

Dentro de este panorama, muchos de los intelectuales de la época defendieron opiniones diversas sobre la genial novela, muchas veces motivadas por meras impresiones subjetivas. Pongamos algunos ejemplos. Montesquieu, en sus Lettres Persanes (1721), criticó duramente la literatura española, pues, según él, « vous pourrez trouver de l'esprit et du bon sens chez les Espagnols, mais n'en cherchez point dans leurs livres [...] Le seul de leurs livres qui soit bon est celui qui a fait voir le ridicules de tous les autres ${ }^{12}$. Sin embargo, el francés caía en una contradicción al alabar a los cuerdos-locos como don Quijote en De l'esprit des lois (1748) : "Comme il y a une infinité de choses sages qui sont menées d'une manière très folle, il y a aussi des folies qui sont conduites d'une manière très sage $»^{13}$.

La lectura del Quijote no escapa el marcado anti-españolismo imperante en Francia durante buena parte de la centuria, una iberofobia que puede explicarse desde el desarrollo del orgullo patrio francés. En función de un exacerbado sentimiento nacionalista, los Enciclopedistas lanzaban dardos envenenados al corazón de la cultura española. Como botón de muestra está el severo ataque de Masson de Morvilliers en L'Enciclopedie Méthodique (1782), donde el autor afirmaba sin ningún tipo de reservas que España no había contribuido en absoluto al desarrollo de la civilización europea. Cioranescu destaca precisamente las dificultades de asimilación del Quijote en la Francia clásica en base a razones interculturales:

L'image du monde, tel que le conçoit le baroque espagnol, doit faire donc un triple saut mortel, avant d'arriver à son destinataire, le public français. Elle n'y laisse pas qu'une plume, mais le message arrive malgré tout [...] C'est par la porte

\footnotetext{
9 Sermain, « La fin de Don Quichotte».

10 Jean-Paul Sermain, "Méduse-marionnette : La vie de Marianne de Marivaux (1728-1741) et l'héritage de Don Quichotte », Études françaises, 42, 1 (2006), págs. 111-125; 114.

11 Jean Marie Goulemot, Lydia Vázquez y Juan Manuel IbeAs, 288.

12 Charles Louis de Secondat, barón de Montesquieu, «Lettres persanes», Euvres complètes, París, Chez Lefèvre, 1835 [1 $1^{\mathrm{a}}$ ed. 1721], págs. 1-110. 55.

13 Charles Louis de Secondat, barón de Montesquieu, «De l'esprit des lois», Euvres complètes, París, Chez Lefèvre, 1835 [1ª ed. 1748], págs. 189-528. 454.
} 
étroite que fait son entrée une littérature moderne qui l'est encore, fondée sur la dialectique du masque et du visage, l'apparence et la réalité, l'être et l'exister, l'engaño comme condition normale de l'environnement et le desengaño ou désabusement comme aboutissement d'un choc fatal entre le vouloir et le pouvoir de l'individu' ${ }^{14}$.

La Encyclopédie (1751-1772) recoge varias alusiones (redactadas por Louis de Jaucourt) a don Quijote y a Cervantes. Se menciona al par protagonista en la entrada enciclopédica sobre lo ridículo, afirmando que el caballero resulta ridículo por sus ideas sobre la caballería, mientras que el escudero lo es por sus delirios de grandeza y sus ansias de fortuna. En ambos casos subyace, según el artículo, la intención paródica: «Mais il semble que l'auteur se moque de tous deux, et qu'il leur souffle des choses outrées et bizarres, pour les rendre ridicules aux autres, et pour se divertir lui-même ${ }^{15}$. Se hace hincapié en don Quijote en la entrada sobre la caballería errante, como no podía ser de otra manera, aunque con una definición que dejaba traslucir la iberofobia a la que antes aludíamos y que no servía sino para justificar el odio y los prejuicios hacia España entre los intelectuales del momento:

Cette bravoure romanesque des anciens chevaliers étoit autrefois la chimère des Espagnols, chez qui il n'y avoit point de cavalier qui n'eût sa dame, dont il devoit mériter l'estime par quelqu'action hérö̈que. Le duc d'Albe lui même, tout grave \& tout sévère qu'il étoit, avoit, dit-on, voué la conquête du Portugal à une jeune beauté. L'admirable roman de dom Quichotte est une critique fine \& de cette manie, \& de celle des auteurs Espagnols à décrire les avantures [sic] incroyables des chevaliers errans ${ }^{16}$.

Curiosamente, Jaucourt es también autor de la entrada correspondiente a Sevilla, ciudad a la que concede el honor de ser la cuna de Cervantes, siguiendo así la hipótesis de Nicolás Antonio, aunque también se hace eco de la polémica suscitada en torno a su lugar de origen siguiendo la biografía de Mayans y Siscar. Jaucourt pide disculpas por la extensión del artículo escudándose en la relevancia de este escritor, al que presenta como el azote de la nación española: «On admiroit ses ouvrages, \& personne ne lui donna du pain ; il mourut dans

14 Cioranescu, Le Masque et le visage, pág. 11.

15 «Ridicule, le », Encyclopédie ou dictionnaire raisonné des sciences, des arts et des métiers, eds. Denis Diderot y Lucien d'Alembert, vol. 29. [RET - SAP], Ginebra, Chez Léonard Pellet, 1778, págs. 228230; 229.

16 «Chevalier », Encyclopédie, vol. 7 [CHA - CHR], 1788, págs. 689-691; 694. 
l'indigence, à la honte de sa nation; mais son nom ne mourra jamais $»^{17}$. En lo que se refiere al Quijote, la entrada no deja de elogiar ciertas virtudes, como la perseverancia del personaje en la defensa de sus ideales frente a la lógica del entorno y sus acertados juicios en los asuntos que no atañen a las caballerías. Alaba, asimismo, las historias secundarias, que denomina " rencontres extravagantes » cuyo fin, se dice, es evitar el aburrimiento a través de otras intrigas distintas a la principal. Considera estos relatos «nouveaux et vraisemblables » : « Le style est approprié au caractère des personnages \& des sujets. Il est pur, doux, naturel, juste $\&$ si correct, qu'il y a peu d'auteurs espagnols qui puissent aller du pair avec Cervantes à cet égard [...] Enfin, les raisonnemens [sic] sont pleins d'esprit, le nœud est habilement caché, \& le dénouement heureux $»^{18}$. Se trata de una visión razonablemente comedida si tenemos en cuenta la descripción de España que ofrece el propio Jaucourt. Pinta a Carlos V y Felipe II como auténticos tiranos que deseaban, mediante la expansión imperial, destruir la Cristiandad y a los españoles, a los que tilda repetidamente de holgazanes y desconocedores de la riqueza de su patrimonio, con el que otras naciones mercantilizan.

Parece que es Jaucourt quien, en su colaboración en la anónima Bibliothèque Raisonnée des ouvrages des savans de l'Europe, publicada en Ámsterdam en francés, está detrás de la crítica al Quijote de Avellaneda, cuyo mérito ni siquiera le merece la comparación con el precedente cervantino: «L'anonyme crut se donner du relief en disant des injures à Cervantès; Mais elles ne firent que le rendre plus méprisable \& augmenter le désir qu'on avait de voir une suite de cet Ouvrage de la main même de Cervantès ${ }^{19}$.

Fue el propio Voltaire, por su parte, quien se comparó a sí mismo con don Quijote $^{20}$, y pensó que sus ambiciones encontrarían un final desolador similar al del ingenioso hidalgo, viéndose como un defensor de las causas perdidas. En consecuencia, también asimiló el idealismo del personaje al afirmar que: «l'histoire dit ce qu'on fait; un bon roman, ce qu'il faut faire $»^{21}$. Al igual que Lesage y otros enciclopedistas, Voltaire también veía a don Quijote reencarnado

\footnotetext{
17 « Seville », Encyclopédie, vol. 30 [SAQ - SHU], 1779, págs. 992-999; 999.

18 «Seville », Encyclopédie, 995-996.

19 «Article XI. Nouvelles littéraires d'Oxford », Bibliothèque Raisonnée des ouvrages des savans de l'Europe pour les mois de juillet, août, septiembre 1738, vol. 21, Amsterdam, Chez J. Wetstein et G. Smith, 1738, págs. 227-237. 232-233.

20 La anécdota, narrada por Jean Orieux, está recogida en Ian W ATT, Myths of Modern Individualism, Cambridge, Cambridge University Press, 1997, pág. 223: Al llegar a la ciudad alemana de Hertford, un centinela le hizo identificarse y él respondió: « Don Quijote » .

21 Voltaire, «A Madame Élie de Beaumont », Euvres complètes de Voltaire, vol. 12, Correspondance générale, París, Chez Furne, 1837 [1ª ed. 1764], pág. 486.
} 
en distintos personajes históricos, como Carlos II de Suecia y San Ignacio de Loyola (a quien su historiador comparó también con el héroe de Cervantes). Es interesante observar que Voltaire aludía al rey como un soldado más, apoyando así la hegemonía de las Armas sobre las Letras, discurso esencial que pone de manifiesto el ideal anacrónico de don Quijote. La crítica ${ }^{22}$ ha señalado además una posible influencia de Don Quijote en algunos pasajes de obras de Voltaire, como Le Prude (1739) y Candide (1759), donde se critica el optimismo exacerbado.

Lesage tradujo al francés de forma bastante libre la continuación de Avellaneda bajo el título de Les Nouvelles aventures de don Quichotte (1704). La narración de «El curioso impertinente» fue llevada a la escena con el mismo título por M. Nericault Destouches en 1711 y Beaumarchais se inspiró en Sancho Panza para caracterizar al protagonista de Le Mariage de Figaro (1778). Dentro de la producción dramática de la época napoleónica, don Quijote ocupa un lugar predominante, aunque se trata de reescrituras de episodios concretos, muchas veces entremezclados, que revisten poca hondura ${ }^{23}$. En el cambio de siglo (1800), Jean François de La Harpe considera en su Cours de littérature ancienne et moderne (1799-1805) que, mediante su novela, Cervantes ha aniquilado todos los demás libros españoles. Destaca la locura de su protagonista, las gracias de Sancho, y, muy especialmente, la novelita sobre el impertinente Anselmo.

Posicionándose del lado de los «modernos», el abate Jean-Baptiste Dubos (1719) reaccionó contra la crítica de Pierre Perrault, y estableció una comparación entre la novela cervantina y el Hudibras (1663-1678) de Samuel Butler, afirmando lo siguiente: «Je ne sais que Don Quichotte, héros d'un genre particulier, dont les prouesses soient aussi connues des étrangers que des compatriotes de l'ingénieux espagnol qui lui a donné l'être ${ }^{24}$. Del mismo modo, el abate Nicolas Troublet no consideró a don Quijote un loco, sino un fanático, y como tal, «[il] peut être un homme plein d'esprit \& même de raison à certain égards ${ }^{25}$.

22 BARDon, Don Quijote en Francia en los siglos XVII y XVIII, pág. 707.

23 Uno de los autores más prolíficos es Jean-Guillaume-Antoine Cuvelier, autor de L'Empire de la folie, ou la Mort et l'apothéose de Don Quichotte (1799), rebautizada como Don Quichotte et son écuyer Sancho Pança (1810). En 1816 escribiría Sancho Pança dans l'isle de Barataria.

24 Jean-Baptiste Dubos, Réflexions critiques sur la poésie et sur la peinture, Vol, 1, París, Chez PierreJean Mariette, 1733 [1 $1^{\mathrm{a}}$ ed. 1719], pág. 107. Canavaggio (Don Quichotte, du livre au mythe, París, Fayard, 2005, pág. 98), apoyándose en el libro de Bardon (1931), menciona una obra de Dubos titulada Défense de Don Quichotte que no hemos podido localizar. La citada obra de Dubos incluye reflexiones conjuntas sobre don Quijote y Hudibras (págs. 32 y 139).

${ }_{25}$ Nicolas Charles Joseph Troublet, «De l'Esprit», Essais sur divers sujets de littérature et de morale, París, Chez Briasson, 1754 [1 $1^{\text {a }}$ ed. 1735], págs. 294-346; 329. 
Por otra parte, consideramos errónea la visión de quienes afirman que las alusiones y apropiaciones de Diderot no revisten hondura alguna ${ }^{26}$, pues, Diderot, quien comparó a Dulcinea con la Virgen, recreó los relatos cervantinos intercalados a modo de historias que se interrumpen constantemente en un bucle infinito. Se trata de los récit-tiroir que aparecen en Jacques le fataliste et son maître (1796), donde, además, el francés crea una pareja similar a don Quijote y Sancho. En este caso, el protagonista es el acompañante, un parlanchín que filosofa continuamente provocando la exasperación de su amo, a quien cuenta, con muchas digresiones, también al estilo de Sterne, la historia de sus amores. El célebre íncipit, en el que se presenta a los dos personajes en medio de un viaje, recuerda, en cierto modo, al inicio de la narración cervantina.

Rousseau vio en don Quijote a un defensor de los derechos humanos, y él mismo aparece, para algunos críticos, como una reencarnación del personaje ${ }^{27}$. El escritor defendió la dignidad del personaje al expresar su temor de que el rechazo que este sufre dentro de la historia pudiera trasladarse fuera de la misma, constituyendo una injusta burla del idealismo que ha tomado por bandera.

Bernardin de Saint Pierre, autor de la triste historia de Paul et Virginie (1788), alude a la silueta de don Quijote en un estudio sobre botánica. Es más interesante, sin embargo, la reflexión que Saint Pierre nos ofrece, siguiendo a Rousseau, acerca del valor de la obra de Cervantes, a quien compara con Rabelais:

C'en était fait du bonheur des peuples, et même de la religion, lorsque deux hommes de lettres, Rabelais et Michel Cervantès [...], s'élevèrent, l'un en France, et l'autre en Espagne, et ébranlèrent à la fois le pouvoir monacal et celui de la monarchie. Pour renverser ces deux colosses, ils n'employèrent d'autres armes que le ridicule, ce contraste naturel de la terreur humaine. Semblables aux enfants, les peuples rirent et se rassurent : ils n'avaient plus d'autres impulsions vers le bonheur que celles que leurs princes voulaient leur donner, si leurs princes alors avaient été capables d'en avoir ${ }^{28}$.

26 Goulemot, VÁzQuez e Ibeas, «La locura en el siglo de la razón», pág. 271.

27 Estos paralelismos entre la vida de Rousseau y el personaje de don Quijote pueden mostrar la influencia del hidalgo en la mentalidad de sus lectores. Además, Rousseau aparece como un precursor de la interpretación romántica del personaje en Francia, cuyos inicios data Bardon en 1761, año de publicación de La Nouvelle Helö̈se (Don Quijote en Francia en los siglos XVII y XVIII, pág. 634). Esta novela epistolar incluye a dos personajes, Saint Preux y milord Edouard, que unen la galantería hidalguesca y la búsqueda de una quimera a través del matrimonio con el individualismo y la sinrazón.

28 Bernardin de SAINT PIERRE, «Récapitulation », Oeuvres complètes, vol. 2, Études de la nature, Bru-

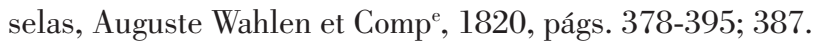


En cuanto a las obras que acusan la influencia de Don Quijote, hay que destacar la anónima Le Désespoir amoureux (1715), que intercala una serie de historietas de amor en las que el propio don Quijote lleva a cabo una serie de fanfarronadas. En la Histoire des imaginations extravagantes de Monsieur Oufle (1710), del abate Bordelon, el protagonista se vuelve loco por los libros de magia y brujería, haciéndose rodear de objetos y materiales para la astrología y extraños rituales. Se cree un licántropo (un loup garou, a imitación de lo que cuenta Rutilio en Persiles y Sigismunda) y lleva a cabo una serie de excentricidades para conseguir tanto el amor (especialmente, el de Dulcine, nombre que adapta al francés el de la amada de don Quijote) como el reconocimiento general y que, a pesar de los desengaños, no pierde su fe en el más allá. Además, comete toda clase de simplezas que le valen las burlas de su entorno. Como don Quijote, sus familiares intentan devolverle la cordura, pero él sigue pensando que los diablos (representantes de los encantadores) le persiguen bajo la apariencia de distintos animales e insectos. La novela incluye abundantes citas y divagaciones intercaladas sobre los aparecidos, los hechiceros y las criaturas infernales.

El Pharsamon ou Les Folies romanesques (1737) de Marivaux se publicó inicialmente con dos títulos alternativos bien significativos: Le Don Quichotte françois (edición de la Haye de 1739) y Le Don Quichotte moderne (edición parisina de 1781). La obra gira en torno a Pierre Bagnol y su servidor, Colin Michard, un glotón que recuerda indefectiblemente a Sancho. Bagnol busca, no sin pasar bastantes penurias, conseguir el amor. La amada en este caso es Cidalise, de quien el muchacho se enamora a primera vista en un paseo por el bosque cuando ella va vestida de hombre para purgar una desgracia amorosa del pasado. Entonces decide convertirse en el caballero Pharsamon y llamar a su criado Cliton. Acude a cortejar a Cidalise en su castillo, pero se encuentra con la oposición de las familias. Como señala Canavaggio, el héroe no tiene la apariencia ni edad de don Quijote y la amada resulta estar tan loca como él ${ }^{29}$. Sin embargo, las burlas y los ridículos que Pharsamon sufre constantemente le equiparan al precedente cervantino.

En la inacabada La Vie de Marianne (1731-1742), Marivaux va a apropiarse de las técnicas narrativas cervantinas a la manera de Fielding o Smollet: deja entrecortadas las aventuras de sus héroes en el punto álgido, borra totalmente la voz del narrador para dotar a su relato de un hechizo de verosimilitud y multiplica las digresiones e historias inacabadas. De este modo, sobrepasa el nivel de la comicidad para adentrarse en la antinovela, marcando así un nuevo aspecto

29 Canavaggio, Don Quichotte, du libre au mythe, pág. 102. 
de la herencia cervantina en la novela francesa de la época. Aquí, como en Le paysan parvenu (1734) la trasposición quijotesca opera mediante el intertexto de las novelas inglesas de los años 40, de las que extrae los siguientes recursos cervantinos: «l'invention d'un genre comique capable de traiter de façon positive la réalité commune de la société, de peindre un héros quelconque (enfant trouvé, paysan ou bâtard) et de dénoncer les ridicules sociaux $»^{30}$.

Por último, Marivaux dirigió una parodia a la obra de Fénélon, Les Aventures de Télémaque) que obtuvo el reconocimiento de Montesquieu, entre otros, por su velada defensa de los derechos individuales frente a los reales, (la cual valió a Fénélon la caída en desgracia en tiempos de Luis XIV). El Telémaco de Fénélon se sitúa en la línea de los clásicos al continuar las aventuras del hijo de Ulises en busca de su padre. Bajo el título de Télémaque travesti, Marivaux ridiculiza el original creando a dos personajes que se creen (de ahí el título de la obra) Telémaco y su acompañante. Pero mas allá del efecto cómico perseguido, la parodia reviste un tono de antinovela, ya que se degradan las aventuras y el lenguaje cayendo de lo heroico a lo vulgar.

En la escena dramática ${ }^{31}$, el interés se reaviva en los teatros de las Foires ${ }^{32}$ (1715-1730) con reescrituras que también conciernen las historias secundarias, a las que los autores imprimen su propio sello, llegando a alterar considerablemente el original cervantino. En otras ocasiones se trata de reelaboraciones de obras anteriores, también relacionadas con Cervantes. Estas piezas del teatro pre-revolucionario se centran en episodios concretos, especialmente el gobierno de Sancho Panza, presentados siempre desde la óptica de la comicidad y lo grotesco y al estilo de Molière ${ }^{33}$. Aunque no se trata de obras muy relevantes ni profundas, la persistencia del tema deja entrever un gusto popular por la novela de Cervantes y por sus personajes, ya que, a pesar del título, estas

30 Jean-Paul SERmain, « Méduse-marionnette », pág.117.

31 Cf. Christophe Couderc, " Don Quichotte et Sanche sur la scène française (XVII ET XVIII siècles) », Mélanges de la Casa de Velázquez 37, 2 (2007), URL <http://mcv.revues.org/1655>.

32 La denominación de "Théâtre de la Foire" corresponde, en los siglos XVII y XVIII, a teatros populares que se daban en algunos barrios de París con motivo de las fiestas locales. Los más célebres fueron los teatros de la Foire de Saint-Germain, Saint-Ovide y Saint-Laurent.

33 Algunas obras que actualizan las historias intercaladas son: Le Jaloux désabusé (1709) de Campistron; Le Curieux impertinent (1710) de Destouches y Le Jupiter curieux impertinent (1711) de Fuzelier. He aquí también otras que reelaboran episodios concretos : La Prévention ridicule, ou la Caverne de Montesinos (1735), pieza moralizante del autor oculto bajo el seudónimo Messire Jean Nicolas de Brasey, comte de Lyon ; Les noces de Gamache (1722), ballet cómico de Fuselier; se han documentado alusiones esporádicas en Arlequin et Scaramouche vendangeurs (1710), Arlequin défenseur d'Homère (1715) de Fuzelier; Arlequin toujours Arlequin (1753) firmada por Lelio Fils, Dominique et Romagnesi (corregimos a Cioranescu [Le Masque et le visage, pág. 546] que considera esta obrita anónima); La Fille inquiète, ou le besoin d'aimer (1754) de Jacques d'Autréau; finalmente, Charles-Antoine Coypel reescribe el ballet herö̈cómico de Pichou Les folies de Cardénio (1720). 
obras no sólo se centran en Sancho, sino que don Quijote suele aparecer como co-protagonista. Algunos ejemplos son: Sancho Pança (1705), de Bellavoine; Sancho Pança dans son île, de Poinsinet; Sancho Pança, gouverneur (1713), de Dancourt, y Le Bagatelle ou Sancho gouverneur (1727) de Thierry, (ambas adaptan escenas que aparecían en la obra de De Guérin); Sancho, gouverneur de l'île de Barataria (1711) de Fuselier; o Sancho, gouverneur, de Nougaret (1738), o incluso, a través de la influencia indirecta, se puede relacionar con el gobierno de Barataria el Démocrite amoureux (1700) de Regnard ${ }^{34}$.

A partir de 1750 empiezan a desarrollarse los ballets, que se mantienen, en su mayoría, en la línea cómica heredera directa de la estética barroca. En este caso, los episodios en casa de los duques son los más admirados, pero Sancho sigue teniendo protagonismo ${ }^{35}$. Tal vez la más relevante sea Don Quichotte chez la duchesse (1743), de Boismortier, en la cual, el duque disfrazado de Merlin encomienda a don Quijote descender a la cueva de Montesinos para liberar a Dulcinea encantada. Altisidora, para vengarse del desdén sufrido a manos de don Quijote, le hace creer que él y Sancho han sido transformados en oso y mono, respectivamente. No obstante, don Quijote termina siendo emperador del Japón y Sancho gobierna su preciada isla.

\section{Lecturas del Quijote durante la Revolución Francesa (1789)}

Los acontecimientos que precedieron al estallido de la revolución francesa influyeron también el ámbito literario. La interpretación del Quijote no podía ser ajena a este nuevo contexto. El propio personaje ha sido, en muchos casos, visto como un revolucionario avant la lettre, pues, de entre las múltiples advocaciones que se le han atribuido, las que más han contribuido a su inmortalidad son, precisamente, su rol como santo patrón de las causas injustas y su tenacidad en la defensa de sus propios ideales, sean estos más o menos adecuados y/o realizables. Ambas le han granjeado, desde la perspectiva historicista, la admiración por parte de los grandes defensores e ideólogos de la revolución. Su versatilidad le ha permitido ser aclamado tanto en relación con los valores de los

34 Otras alusiones más imprecisas se encuentran en Dom Castagne, chasseur errant (1700) de Potier de Morais, así como en la comedia de Marivaux ambientada en Barcelona Le Prince travesti ou l'Illustre avanturier (1724) y en el drama histórico de P. Ducerceau Les incommoditez de la Grandeur (1734).

35 Así sucede en Sancho Pança dans son île (1762) ópera bufa de Poinsinet, a la que se suma el ballet-pantomima Don Quichotte chez la Duchesse (1734) de Pannard ; Le Fou lié ou Don Quichotte (1773), comedia en un acto de Labussière ; Le Programme des Aventures de Don Quichotte (1778) pantomima en tres actos de Pleinchesnne. 
defensores de la paz, como de la guerra, como del comunismo y del pacifismo, tanto para bien como para mal, caracterizando al personaje como una moneda que tiene más de dos caras. La enseñanza que se puede extraer de las andanzas de don Quijote es la de la abigarrada defensa de los ideales, aunque estos vayan a contracorriente: «los derechos humanos, el ideal de libertad, la resistencia a la opresión, la democracia y el sagrado derecho a la rebelión contra la injusticia» ${ }^{36}$ de la que se han hecho eco escritores y personajes históricos tan heterogéneos como Rousseau, Von Humboldt, Byron, Danton, Bolívar o Zapata.

En Francia, durante y tras la revolución, la obra de Cervantes pasó a ser leída como una crítica social que dejaba entrever una oposición simbólica entre el ideal (travestido de locura), encarnado por don Quijote, y lo real (el sentido común), representado por su fiel escudero. Si a lo largo de gran parte del siglo XVIII se había leído el Quijote desde una postura filosófica, la interpretación post-revolucionaria incidiría en su sentido ético: la lucha del individuo frente a la sociedad. Como indica Colahan ${ }^{37}$, uno de los personajes más admirados es Marcela, no por su exaltación de ideas feministas o su rebeldía frente a la autoridad patriarcal, sino por su lucha individual por los derechos humanos, ideales con los que los revolucionarios franceses se identificaban. De esta forma, la obra cervantina se convertía en una alegoría social que encarnaba los valores de la revolución ${ }^{38}$, y bajo la influencia de este radical cambio de rumbo de la historia, la cultura y la literatura europeas, el Quijote pudo comenzar a desvincularse de la interpretación cómica inicial (válida en el momento, pero que la crítica posterior consideró superflua e incompleta) para albergar una serie de valores universales.

En los años postrevolucionarios surge una nueva traducción, llevada a cabo por Florian (1799), sobrino-nieto de Voltaire. Se trata de una versión casi pacifista por su edulcorada reducción de los lances caballerescos y su deleite en los requiebros amorosos, que pretendía satisfacer, según explica el autor, el gusto francés. En el Prefacio se alude ya a la nueva visión de los avatares del protagonista:

36 Washington Daniel Gorosito Pérez, «Don Quijote, intelectual y revolucionario», Letras Uruguay, espacio de difusión de la literatura uruguaya y latinoamericana, (2015): 3 de junio de 2016: http://letrasuruguay.espaciolatino.com/gorosito_perez_washington/don_quijote_intelectual_y_revolucionario.htm.

37 Clark Colahan, «El Don Quichotte de Florian: la Revolución a la pastoril», Cuadernos de Estudios del Siglo XVIII, 24 (2014), 49-65.

38 Esto no es nada nuevo, pues cada época histórica interpreta las obras literarias conforme a sus principales ideas y directrices. El Quijote ha sido leído e interpretado desde casi tantas perspectivas y movimientos como han existido. En esta versatilidad radica esencialmente su grandeza, y su carácter diferenciador, mítico, respecto a otras obras cumbres de la literatura. 
Tout ce que dit le héros, lorsqu'il ne parle pas de chevalerie, semble dicté par la sagesse pour faire aimer la vertu ; son délire même n'est qu'un amour mal entendu de cette vertu. Don Quichotte est fou dès qu'il agit, il est sage dès qu'il raisonne ; est comme il est toujours bon, on ne cesse point de l'aimer ; on rit de lui, et l'on s'y intéresse. On le sait insensé, et on l'écoute. Cervantès est peut-être le seul homme qui, par une invention aussi neuve, aussi différente de tout ce que l'on connoissoit, ait forcé ses lecteurs de suivre longtemps, sans se fatiguer, les actions d'un extravagant dont on se moque sans cesse, et qu'on ne peut jamais mépriser; dont on plaint toujours le délire, et dont on admire souvent la raison [...] réunion si rare de la morale et de la gaieté, de la finesse et du naturel, de l'imagination la plus brillante, et de la diction la plus pure [...] l'auteur qui remplit son livre de caractères tous différents quoique presque tous aimables, et qui, sachant si bien nous attendrir lorsqu'il lui plaît, sait encore nous donner des leçons de vertu, et nous faire rire long temps sans jamais risquer d'alarmer la pudeur la plus délicate ${ }^{39}$.

Florian es también autor de un ensayo, "Des ouvrages de Cervantès », donde recorre y comenta la producción literaria de su admirado autor. Pide comprensión hacia el desafío que Cervantes lanza al incluir en sus obras aventuras inverosímiles: «On doit pardonner à Cervantès, qui avait en lui-même des aventures extraordinaires, d'avoir imaginé qu'elles seraient vraisemblables dans un roman ${ }^{40}$. Resulta cuanto menos curioso que se aluda a las « luces de Cervantes » y de Pablo de Olavide, que conoció bajo el seudónimo del Conde de Pilos, al final del ensayo: "J'ai été guidé par les lumières d'un Espagnol qui aime les lettres autant que sa patrie, et qui a de commun avec Cervantès d'être encore plus célèbre par ses talens que par ses malheurs ${ }^{41}$.

Como antes vimos, la traducción de Florian dio lugar a reescrituras y alusiones a episodios inventados por Robert Challe ${ }^{42}$ y pudo condicionar la lectura de la obra por aquellos que no conocían el original ${ }^{43}$. Se trata de una versión muy alejada ideológicamente de los ideales revolucionarios, de la que extraña que pudiera ser dada a la imprenta sin ningún tipo de traba o censura. Esta traducción no parece explicar cómo don Quijote pudo convertirse en un mitologema revolucionario. Se trata de una instrumentalización del personaje que

\footnotetext{
39 Jean-Pierre Claris de Florian, «Avertissement du traducteur », Oeuvres posthumes de Florian, de l’Académie française, vol. 1, Paris, Chez Menard, 1837, págs. 87-95; 88-90.

40 Florian, «Des Ouvrages de Cervantes». Oeuvres posthumes, págs. 55-71; 70.

41 Florian, «Des Ouvrages de Cervantes», pág. 71.

42 Moner alude a la lanza atribuida a Sancho, que no se halla en el original, y a la transformación del episodio de los leones en avestruces.

43 Michel Moner, «La recepción de Don Quijote en Francia». Centro Virtual Cervantes, 2004. URL <http://cvc.cervantes.es/lengua/anuario/anuario_04/moner/p03.htm>
} 
le hizo más popular pero que, como contrapartida, reducía su valor principal a la simple locura, lo cual no sólo portaba una carga semántica dentro de los parámetros ideológicos del contexto, sino que también posibilitó que su figura pudiera ser utilizada como arma arrojadiza desde uno u otro bando, aunque ello supusiera en la mayoría de los casos una gran contradicción: «Revolucionarios y contrarrevolucionarios no sienten respeto alguno los unos por los otros ni, obligado es decirlo, lo demuestran para con el personaje de Cervantes. Solo pretenden ridiculizar, combatir, derribar» ${ }^{44}$. Sin embargo, esta creciente popularidad permitió que Cervantes empezase a desmontar su propia leyenda negra en Francia al comenzar a ser admirado por su lucha por la libertad (a nivel personal y creativo) así como por su cultivo de la novela pastoril. Los neologismos epónimos derivados de los personajes « quichotte », « quichottisme », «dulcinée », que entran a partir de este momento a formar parte de la lengua común atestiguan lo que serán los cimientos de la interpretación romántica: el Quijote ya no es admirado como un funny book, sino como base de una grave ironía.

La obra maestra de Cervantes comenzó a ser utilizada con fines partidistas desde antes de 1789 por los distintos bandos y colectivos indistintamente ${ }^{45}$. Un vistazo a la propaganda revolucionaria así nos lo indica. El panfleto titulado Ordonnance de pólice de très-haut et très puissant seigneur Sancho Pança, gouverneur de l'isle Barataria (1789) toma como excusa al famoso escudero cervantino para transmitir en el lenguaje del pueblo llano y con los recurrentes y característicos refranes del personaje, una serie de ideas revolucionarias salpicadas de un cierto tono jocoso.

Sancho, gobernador de Barataria, «por la gracia de Dios», establece una serie de normas de convivencia para sus conciudadanos con las que pretende asegurarles: "salus, honos, argentum, atque bonum apetitum " ${ }^{46}$, cita tomada del Malade imaginaire de Molière. Estas normas, organizadas en títulos y apartados, conciernen todos los aspectos de la vida social y comunal, y, responden a un desmantelamiento de las estructuras del antiguo régimen. Se propone, por ejemplo, demoler toda suerte de compromisos involuntarios, sobre todo, el conyugal, los derechos de los privilegiados, el lujo y el boato eclesiásticos..., al tiempo que se aboga por la defensa de los derechos individuales. Las ideas, a

44 Bardon, Don Quijote en Francia en los siglos XVII y XVIII, pág. 918.

45 Es interesante recordar la utilización de la quema de libros, de claras reminiscencias cervantinas, como parte del proceso revolucionario y de represión ideológica (los bibliocaustos se convertirían en episodios frecuentes en épocas de dominación, especialmente durante el nazismo). Por ejemplo, en la insurrección agraria que se produjo en las áreas rurales, durante la época de La Grande Peur, se quemaron libros que versaban sobre la servidumbre y los derechos feudales.

46 Ordonnance de pólice de très-haut et très puissant seigneur Sancho Pança, gouverneur de l'isle Barataria, París, Chez Garney \& Volland, 1789, pág. 3. 
pesar de tener un trasfondo democrático, son presentadas desde una perspectiva cómica, (como sugiere también la elección del propio personaje), y para corroborarlo, aparece firmando en calidad de secretario el mago Parafaragaramus (la alusión evidencia la influencia de la traducción de Filleau de Saint Martin y la continuación apócrifa de Challe, pues es de allí de donde proviene el personaje). Cobra sentido la cita inicial tomada de Juvenal, vitam impendere vero, con la cual se anuncia ya que el texto sólo debe ser tomado como una alegoría jocosa del proceso revolucionario.

Otro panfleto relevante es el titulado Le trio: dom Quichotte, Chicanneau y Tartuffe au Tartare (1789). En apenas 30 páginas, don Quijote se presenta como un apasionado defensor del viejo orden de la nobleza, del sistema feudal como un resquicio viviente de la gloria de antaño, y entra en combate dialéctico con los dos representantes del nuevo orden. Don Quijote muestra un carácter pendenciero, pues sus primeros parlamentos son llamadas a las armas, y no duda en proferir todo tipo de amenazas a los razonamientos juiciosos de sus colegas, que abogan por una revolución tranquila. De este modo, se presenta el nuevo orden revolucionario como el mundo lógico que don Quijote no logra asumir, mientras que los ideales añejos del caballero resultan coincidir con los de la monarquía y la nobleza. Como podemos ver, se produce aquí un cambio de orientación respecto al carácter original que se atribuía al personaje.

Señalaremos por último la caricatura dirigida al Príncipe de Condé, Luis José de Borbón, de gran riqueza plástica, titulada Marche du don Quichotte moderne pour la deffence [sic] du Moulin des Abus. Se trata de una caricatura anónima del año 1791, en la que Mirabeau aparece como Sancho Panza sentado a lomos de un caballo de madera (posible Clavileño, pero también posible caballo de Troya). Ambos lideran una contra-revolución para liberar al pueblo de las injusticias ejercidas por Luis XVI, cuya testa corona el mencionado molino.

Hay que destacar, no obstante, que don Quijote no fue una figura especialmente aludida durante el periodo revolucionario ${ }^{47}$. Se preferían las personalidades canónicas, especialmente de la época romana, como Scevola, Publicola, Horacio Cocles, Tiberio Graco o Catón de Utica ${ }^{48}$. No obstante, el nombre del ingenioso caballero ha entrado ya en el imaginario colectivo en los años en que se gesta la gran revuelta, y aparece con frecuencia en los discursos revolucionarios con fines militantes. Brisset, contrarevolucionario y futuro girondino, fue apodado «le don Quichotte de l'Humanité »; Gustavo III, « le don Quichotte

47 A pesar de ello, figuras literarias, (como Louis de Rouvroy, duque de Saint-Simon, en sus Mémoires [escritas a mediados de siglo pero no publicadas hasta 1829]), también se sirvieron del ingenioso hidalgo para criticar a sus contemporáneos.

48 Bardon, Don Quijote en Francia en los siglos XVII y XVIII, pág. 908. 


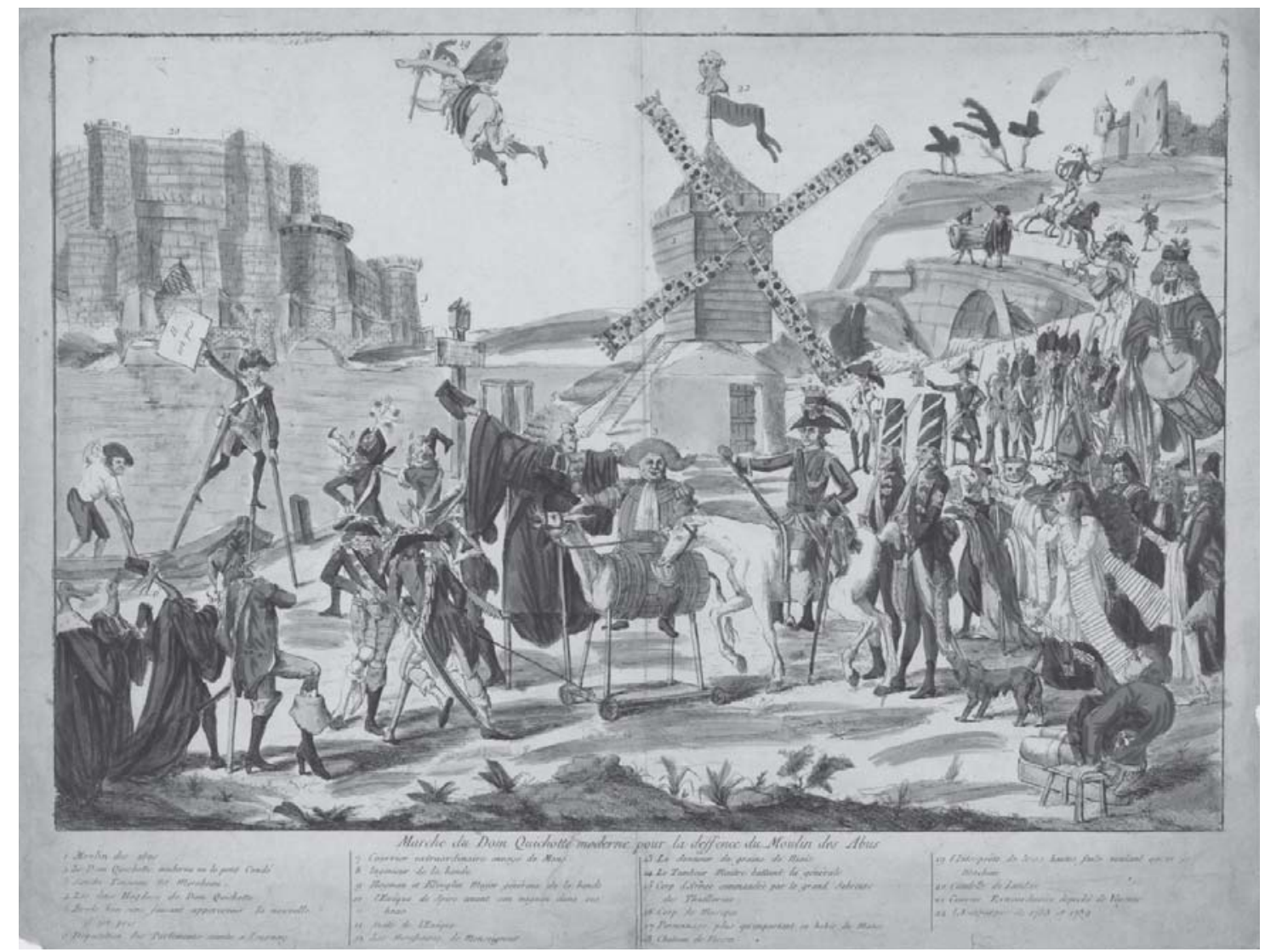

Marche de don Quichotte pour la deffence [sic] du moulin des abus, 1791

du Nord », y Jean-Baptiste de Boyer, marqués de Argens, « le nouveau don Quichotte ${ }^{49}$. Un ejemplo curioso es el que nos ofrece Olympique de Gouges (1748-1793), revolucionaria y defensora de los derechos de la mujer. Aparte de lo que antes se ha dicho, «Don Quichotte du Nord » era el nombre con que Federico II de Prusia se identificaba ante su círculo más íntimo, y con el que la autora se refiere a su sucesor, Federico Guillermo II, sobrino de aquel. Era, asimismo, el sobrenombre con el que se aludía al rey en las obras de Voltaire ${ }^{50}$. Ella misma se considera quijotesca en base al error que cree haber cometido al defender al rey de Francia, que considera un tirano con corona, y aconseja al soberano alemán que le retire su apoyo en los siguientes términos:

Fréderic, si tu es sage, tu évacueras promptement notre territoire ; \& si l'offre que te fait un général non moins habile que valeureux, excite de nouveau ton ambi-

49 Estas alusiones preceden a los Quijotes políticos de comienzos del siglo XIX en Inglaterra, como William Godwin y Edmund Burke.

50 Goulemot, VázQ̨uez e Ibeas, «La locura en el siglo de la razón», pág. 283. 
tion pour terrasser ton ennemi-né, ta défaite même deviendra une conquête aux yeux de ton peuple ; mais, si, comme l'incomparable Don Quichotte de la Manche, tu combats des géants réels, je crains pour toi qu'il ne te reste pas même un moulin à vent pour ta retraite ${ }^{51}$.

Al distanciarse del apodo creado por Voltaire, De Gouges anticipa la interpretación romántica, pues se trata de un héroe solitario que defiende un régimen ya caduco.

Por otra parte, no es raro encontrar alusiones a la obra y al personaje cervantinos en las crónicas de las reuniones de la Asamblea Nacional donde se estaban gestando y debatiendo algunas de las nociones políticas y sociales que habrían de dominar la reciente Edad Contemporánea. Hay quien afirma que Hérault de Séchelles y Danton poseían ediciones del Quijote ${ }^{52}$ aunque esto entra más bien en el terreno de la conjetura. Por poner algunos ejemplos, las alusiones a don Quijote se convirtieron en habituales durante las sesiones parlamentarias previas a la insurrección. El general Édmond Louis Alexis Dubois de Crancé, diputado del Tercer Estado en los Estados generales de 1789 y, posteriormente miembro de la Asamblea Nacional Constituyente, fue denominado « le Don Quichotte des Alpes » durante la Convención, de la que fue también presidente. El sobrenombre le vino atribuido en base a su mentalidad democrática, tolerante (defendía la libertad de los hombres de color) y militarista, pero también por su honorable defensa de la ciudad de Lyon en un ataque contra efectivos mucho más numerosos que los suyos ${ }^{53}$.

Muy distinto tono adquieren las acusaciones a Mirabeau de ser pro-monárquico y de traicionar los acontecimientos revolucionarios ocurridos en las jornadas del 5, 6 y 7 de octubre de 1789. Mirabeau evadió asistir a la Asamblea Nacional de esa fecha en que se planeaba la marcha sobre Versalles declarándose enfermo, pero lo que hizo en verdad fue retirarse en secreto para informar al rey de la insurrección y reaparecer, una noche más tarde, en el frente de batalla. Así se narró su peculiar estrategia: «Voilà Monsieur Mirabeau jouant le rôle de don Quichotte, transformé en visionnaire, qui pense qu'à l'ombre de son sabre, des régimens n'ont aucune offense à redouter ${ }^{54}$.

51 Olympique de Gouges, Adresse au don Quichotte du Nord, París, Imprimerie nationale, 1792.

52 Bardon, Don Quijote en Francia en los siglos XVII y XVIII, pág. 997.

53 Théodose Buretre y Ulysse Ladet, Histoire de la Révolution française, de l'Empire et de la Restauration, vol. 3, París, Librairie Charles Gosselin, 1844, pág. 26.

54 Philippe Joseph Benjamin Buchez y Pierre Celestin Roux, Histoire parlamentaire de la Révolution française ou Journal des Assemblées Nationales depuis 1789 jusqu'à 1815, vol. 7, 1834, París, Paulin libraire, pág. 506. 
Según consta en el Journal des États Généraux, durante el debate en la Asamblea Constituyente del 7 de septiembre de 1789, Jean-Denis Lanjuinais criticó el sistema anglosajón defendido por Montesquieu, Delolme y John Adams, y para hacerlo, calificó a este, el segundo presidente de los Estados Unidos, como un «Don Quichotte de noblesse, le précepteur corrumpu d'un grand seigneur $» 55$.

Al mismo tiempo, en una carta a Dusaulchoy se denomina a los emigrados « les Quichottes des vieux parchemins » ou « quichottes du déspotisme », como símbolo de la deserción a la patria. Su autor se refiere, en concreto, a los emigrados pobres, de quienes afirma que han abandonado su país con la quijotesca quimera de abrazar una causa que les hará morir de hambre ${ }^{56}$. Por otra parte, Prudhomme critica tras su dimisión a Lafayette, a quien califica de charlatán con aires de grandeza que ha hecho mucho mal a la revolución y a quien injustamente le han otorgado un gran poder. Al conocer que le han concedido la espada de honor, Prudhomme exclama: «L'épée qu'on lui donne est plus digne de figurer dans les aventures de don Quichotte que dans les Annales du peuple français ${ }^{57}$.

Hasta el mismísimo Robespierre fue apodado « le Don Quichotte de la Révolution » por Fauchet ${ }^{58}$ para simbolizar que se había dejado llevar por ideales vacuos, mientras que el líder radical se refirió a Desmoulins como un Quijote por haber idealizado las ideas pacifistas de Philippeaux, que representaban la facción de los moderados, y propuso quemar sus obras, abogando así por un castigo ejemplar a la manera que Cervantes relata en su libro ${ }^{59}$. En las arengas revolucionarias Robespierre considera a los reyes como bandoleros que se levantan contra la soberanía popular. Añade que su tarea no consiste en actuar como los « Don Quichotte du genre humain, [mais] d'aider nos plus proches voisins à secouer le joug du despotisme [...] et de nous hâter d'appliquer toutes nos ressources et toutes nos énergies à nos affaires domestiques, pour fixer enfin au milieu de nous la liberté, la paix, l'abondances et les lois ${ }^{60}$.

55 Jean-Denis Lanjuinais, “Du 7 septembre”, Journal des états généraux, convoqués par Louis XVI, le 27 avril 1789, ed. Le Hodey de Saultchevreuile, vol. 3, París, Chez Devaux et Gattey, 1789, págs. 320-332; 321.

56 Anónimo, « Extrait d'une lettre de Cherbourg, en date du 8 oct. à J. F. H. Dusaulchoy ». JosephFrançois-Nicholas Dusaulchoy, Révolutions de France et de Brabant (97), 17 octubre de 1791, págs. 39-50; 46.

57 Étienne CABEt, Histoire populaire de la révolution française de 1789 à 1830, vol. 2, 1839. París Pagnerre, éditeur, 1978, pág. 478.

58 Bardon, Don Quijote en Francia en los siglos XVII y XVIII, pág. 908.

59 Nicholas Viluiaumé, Histoire de la Révolution française, vol. 3, París, Michel Lévy, 1851, págs. 316-317.

60 Maximilien De RobespierRe. «Sur la conduite de la Convention nationale envers le général Dillon et sur les príncipes que les répresentans de la nation doivent adopter dans la guerre actuelle », Oeuvres complètes, vol. 5, Lettres à ses commetans, ed. George Laurent, París, Aux bureaux de la Revue historique de la révolution française, 1961, págs. 57-65; 60. 
Pasados los años más duros de la revolución, la presencia de don Quijote se hace especialmente relevante en tiempos del directorio. Como botón de muestra nos acercaremos ahora a los periódicos, con exponentes tan curiosos como Le Mot à l'oreille ou le don Quichotte des dames, diario republicano del que sólo vieron la luz ocho números entre los años 1797 y 1798. Se trata de una publicación propagandística donde se presentaban los acontecimientos más importantes narrados por un tal ciudadano don Quijote. A él se le dirigían cartas de los lectores, y él mismo narraba sus aventuras parisinas a través de los enclaves más representativos en una sección denominada « Variétés » cuyo fin principal, según se afirmaba, era hacer reír a los lectores. Se narra su encuentro con una limonera en Les Halles, los paseos con la llamada «ciudadana» Dulcinea por los Campos Elíseos (a quien enseña la ciudad de París, para que aprenda los modales de la gran ciudad) y su visita a la catedral de Notre Dame. Una de las más disparatadas aventuras es la que lleva a don Quijote a ocultarse dentro de un confesionario y escuchar por error la confidencia de una feligresa que relata un pequeño affaire con un cura. Don Quijote le recomienda una curiosa penitencia: abandonar su hogar y encomendarse al valeroso caballero. En la segunda mitad del periódico se incluía un poema y el resumen de las sesiones del Corps Législatif.

Un artículo anónimo en Le Journal de Paris (1799) alude a Cervantes como escritor inmortal, como ya hiciera Geoffroy de Grandmaison, y a don Quijote como honorable defensor del viejo imperativo caballeresco del amor incondicional a la dama. Esta característica, se afirma, aseguró la fama y trascendencia del personaje y del autor que le dio la vida. Corroboramos, con Bardon ${ }^{61}$, que esta aseveración abre el camino a la interpretación romántica.

El artículo en Le Spectateur du Nord (1799) motivado por la reciente aparición de la traducción de Florian elogia así la obra de Cervantes: "C'est la satyre la plus fine, non seulement des romans de chevalerie, mais de la chevalerie elle-même, et nous sommes peut-être, trop loin d'elle, pour sentir toute la philosophie de l'Auteur, qui sait en livrer les préjugés et les ridicules à la risée de ses lecteurs ${ }^{62}$. Califica el Quijote de monumento y gloria de España. Prosigue aludiendo al tópico latino del castigat ridendo mores: « à la naiveté, à la bonne plaisanterie, à la vérité des portraits Cervantès joint constamment l'art d'instruire en amusant $»^{63}$. Admira el carácter filosófico y la hondura de los discursos donde expone razonablemente su visión del mundo, que contrastan

61 Bardon, Don Quijote en Francia en los siglos XVII y XVIII, pág. 895.

62 «Don Quichotte de la Manche, traduit par Florian, extrait», Le Spectateur du Nord 12, 1799, págs. 202-219; 202.

63 «Don Quichotte de la Manche, traduit par Florian, extrait», 206. 
con la imposibilidad de hacer triunfar sus ideales, anticipando así de nuevo la interpretación romántica. El periodista admira en Florian la dulcificación de ciertos pasajes donde tanto don Quijote como Sancho pasaban muchas penurias y castigos y termina incluyendo, a modo de ejemplo, varios episodios en los que se deja traslucir el buen juicio del protagonista, como el Discurso de las Armas y las Letras y los consejos a Sancho a su llegada al gobierno de Barataria. Finaliza reiterando el mérito de la obra de Cervantes: « d'ailleurs, parmi ceux d'aujourd'hui, il y en a si peux qui approchent du mérite de don Quichotte ${ }^{64}$.

En la escena dramática revolucionaria destacan como novedad las óperas basadas en episodios de la vida del propio Cervantes, como su evasión de Argel en Michel de Cervantès (1794), de Gamas y Foignet. Hay que tener en cuenta que no existía la libertad de elección respecto a los géneros que se podían o no representar. Esta característica, resquicio del antiguo régimen, hizo que el privilegio acordado al recién inaugurado Théâtre de Monsieur limitase el repertorio a óperas bufas de estilo italiano, parodias en francés y comedias de todo tipo. Para poder representar allí su opereta Le Nouveau don Quichotte de Stanislas Champein (25 mayo 1789) el autor tuvo que inventarse un seudónimo italiano ${ }^{65}$. La obra se centra en el embrollo amoroso entre don Quijote, enamorado de Claire, a la que encierra en un castillo y a la que pretende seducir con ademanes de caballero. Por otra parte, Dorlis, el verdadero amor de Claire, ayudado por Crispin, se finge caballero para jugarse el amor de Claire en un combate que termina con don Quijote vencido y los amantes desposados. El tono jocoso reviste poca hondura, pero existe una clara reminiscencia al propio original, como la reescritura de la decisiva pendencia entre don Quijote y el Caballero de la Blanca Luna al final de sus aventuras. Algunas peripecias también recuerdan al Berger extravagant de Sorel, como cuando Dorlis, para rescatar a su malandrín criado Crispin, que se ha escondido en un árbol podrido, parte en dos el tronco en un arranque caballeresco. Para ponerse a salvo, Crispin debe esconderse al lado de Claire, provocando así los celos de su tutor.

Otros títulos significativos del teatro revolucionario son: la disparatada Nicodème dans la Lune ou la Révolution pacifique (1790), de Beffroy de Reigny, apodado «le cousin Jacques»; la polémica L'Ami des lois (1793), que llegó a estar prohibida por presentar de forma velada alusiones a personajes contemporáneos (esta obra incluía un personaje llamado don Quijote que fue inter-

64 «Don Quichotte de la Manche, traduit par Florian, extrait», 219.

65 Patricia Courche-Savarit, "La destinée du Nouveau Don Quichotte », Un siècle de spectacles à Rouen (1776-1876), Actes du colloque organisé à l'Université de Rouen en novembre 2003, eds. Florence Naugrette y Patrick Taïeb. CÉRÉdI, 2009. http://ceredi.labos.univ-rouen.fr/public/?la-destinee-du-nouveau-don. html. 
pretado por el marqués de Forlis ${ }^{66}$ ), y la más interesante, desde nuestro punto de vista, Le Philinte de Molière (1790) de Fabre D’Églantine. Se trata de una revisión del misántropo de Molière en la que Alceste se ha convertido en un personaje ejemplar y altruista, que se esfuerza en inculcar la virtud a sus contemporáneos. La alusión a don Quijote hace entrever una reinterpretación de su idealismo, del que se extrae una lección positiva que anticipa la visión de los románticos.

Como manifestación del interés suscitado por las aventuras del ingenioso hidalgo cabe señalar el trabajo de erudición llevado a cabo por Louis Dutens, quien firma en 1796 unas Tables génealogiques des héros des romans en las que se propone resumir de modo enciclopédico (es decir, ordenado y descrito) los personajes que habitan en la biblioteca de don Quijote, a las cuales añade aquellos provenientes de las obras mencionadas o evocadas en algún momento por cualquiera de los personajes de la novela. Este ambicioso proyecto adolecía de bastantes vaguedades e imprecisiones, además de clamorosos olvidos, pero no por ello deja de atestiguar un interés fehaciente en el carácter intelectual del personaje devorador y vividor de lecturas. Hay que destacar, especialmente, la dinastía de los héroes idealizados por don Quijote (Orlando, Palmerín y Amadís, entre otros) que establece a modo de árbol genealógico y separados por sus correspondientes obras. Este trabajo podría ser revisado y resultar de interés a los estudiosos de las caballerías, de no ser tan desconocido.

La original visión de Cazotte anticipó sobremanera, desde mediados de siglo, la interpretación romántica del Quijote. Su largo poema en prosa Ollivier (1762) es, probablemente, una de las primeras obras deudoras de la gran novela cervantina desde el terreno de la literatura fantástica y gótica francesa. Desaparece en el protagonista, sin embargo, la intención satírica, ya que él sí es un caballero como don Quijote pretendía serlo, y es en la pareja secundaria formada por Enguerrand y su escudero Barin donde se deja traslucir la impronta del original. Otra diferencia notable, y que justifica la adscripción de la obra al género fantástico, es que las aventuras entre los caballeros y seres imaginarios se presentan como verdaderas. De este modo Cazotte se posiciona del lado de don Quijote, «lo ennoblece al conferir una cobertura de oscura verosimilitud a todas sus ensoñaciones y desazones» ${ }^{67}$.

Finalmente, un autor tan alejado, además de temporal, ideológicamente, de Cervantes como el marqués de Sade no duda en proferir unas elogiosas palabras

${ }^{66}$ Además de estos dos títulos, Bardon (Don Quijote en Francia en los siglos XVII y XVIII, pág. 997) recopila otras menciones esporádicas de algunos autores como Mollet, Mercier, Restif de la Bretonne, St. Juste y Mme Roland.

67 Goulemot, Vázquez e Ibeas, «La locura en el siglo de la razón», pág. 281. 
hacia el escritor que tanto admira aludiendo a la reivindicación romántica de lo medieval y la distinción entre la buena y la mala caballería ${ }^{68}$ :

Certes, si la chevalerie avait inspiré nos romanciers en France, à quel degré n'avait elle pas également monté les têtes au delà des monts? [...] Son immortel ouvrage connu de toute la terre, traduit dans toutes les langues, et qui doit se considérer comme le premier de tous les Romans, possède sans doute plus qu'aucun d'eux, l'art de narrer, d'entremêler agréablement les aventures, et particulièrement d'instruire en amusant. Ce livre, dit Saint-Évremond, est le seul que je relis sans m'ennuyer, et le seul que je voudrais avoir fait. Les douze Nouvelles du même auteur, remplies d'intérêt, de sel et de finesse, achèvent de placer au premier rang ce célèbre écrivain espagnol, sans lequel peut-être nous n'eussions eu, ni le charmant ouvrage de Scarron, ni la plupart de ceux de Lesage ${ }^{69}$.

\section{Conclusión}

Según se ha mostrado en este artículo, dentro del contexto revolucionario se forjó una nueva interpretación del Quijote alejada de la tónica dominante durante el Barroco y el Clasicismo. A la vez que el personaje se hacía más popular se perdía en cierto modo el contacto con la obra original, pero al mismo tiempo se superaba la barrera de lo anecdótico, la comicidad y la sátira, para descubrir un trasfondo simbólico que sería desarrollado por los románticos. No se trató de un boom equiparable al del Quijote en Alemania ${ }^{70}$, y las principales contribuciones se hallan en periódicos y fuentes populares más que en trabajos eruditos o de escritores consagrados, pero el espíritu del pueblo sublevado supo ver en el Quijote cómo los individuos pueden encarnar la razón y el tesón mientras que las fuerzas del poder pueden ser corruptas y partidistas.

Como hemos podido ver, sobre todo en las últimas contribuciones aludidas, don Quijote aparece ante los nuevos acontecimientos como portador de un

68 Cf. Emilio MarTínez Mata, «La influencia del propósito caballeresco en la interpretación del "Quijote" (siglos XVII y XVIII)», Tus obras los rincones de la tierra descubren: Actas del VI Congreso Internacional de la Asociación de Cervantistas, ed. Alexia Dotras Bravo, Alcalá de Henares, Centro de Estudios Cervantinos, 2008, págs. 495-502; 502.

69 Donatien Alphonse François De SADE, Marquis de Sade, Idée sur les Romans, París, Edouard Rouveyre, 1878.

70 El Quijote no sólo fue la novela más leída y admirada por los escritores ingleses y alemanes durante los siglos XVIII y XIX, sino que pudo actuar como elemento cohesionador para los escritores del Sturm und Drang y los plenamente románticos, que manifestaron abiertamente su admiración y consagraron obras de estudio a desentrañar el lado idealista del imaginario cervantino, cuya influencia se observa bajo la forma de reescrituras en muchas de las obras de Goëthe, Schiller, Tieck, y sobre todo, los hermanos Schlegel (cf. BAUTISTA NARANJO 2016). 
idealismo que consiste en sacrificar la vida en nombre de un principio moral superior. Esta y otras ideas, que pueden hallarse en algunos discursos revolucionarios, así como en las obras de Rousseau o Cazotte, serían defendidas a posteriori por Benjamin Constant y Madame de Staël. Dentro de las enseñanzas que el siglo XVIII tomó del Quijote de Cervantes existen dos que nos parecen relevantes por su posterior explotación durante la época romántica: la ruptura entre el punto de vista narrativo y el del personaje y la reivindicación de la libertad del protagonista. Cioranescu resume brillantemente el giro que la historia y la crítica literaria darían a interpretación de las aventuras del ingenioso hidalgo entre la Ilustración y el Romanticismo:

Chez Don Quichotte, l'idéalisme du personnage se heurte à tout instant au mur des réalités. On veut que son histoire soit celle d'un aveuglement : on peut aussi bien dire qu'elle raconte un engagement qui consiste à modifier les données du réel, pour les faire coïncider avec le rêve. Bien entendu que c'est en même temps une erreur des sens, et surtout du jugement ; on n'en avait plus vu d'aussi énorme et d'aussi héroïque, depuis Prométhée ${ }^{71}$.

Y precisamente mediante esta comparación entre don Quijote y Prometeo, figura revitalizada en la literatura francesa del siglo XIX, se apunta hacia un doble nexo común a estos dos personajes: una similar representación de la individualidad humana que se ofrece a sí misma modelos más o menos utópicos como proyectos vitales, y sobre todo, otro concepto esencial en el devenir del Caballero de la Triste Figura, el de mito o relato esencial de ejemplaridad trascendente al tiempo y al espacio que ilumina una problemática inherente al ser humano.

$71 \quad$ Cioranescu, Le Masque et le visage, pág. 547. 